\title{
An analysis of epidemiological data in HLA-typed diabetic children
}

\author{
A. Mustonen ${ }^{1}$, J. Ilonen ${ }^{2}$, Anja Tilikainen ${ }^{3}$, M. Kataja ${ }^{4}$ and H. K. Åkerblom ${ }^{1,5}$ \\ ${ }^{1}$ Departments of Paediatrics and ${ }^{3}$ Mcdical Microbiology, University of Oulu, ${ }^{2}$ National Public Health Institute, Oulu, \\ ${ }^{4}$ National Public Health Institute, Helsinki, and ${ }^{5}$ The Children's Hospital, University of Helsinki, Helsinki, Finland
}

\begin{abstract}
Summary. To clarify the heterogeneity of Type 1 (insulin-dependent) diabetes mellitus, differences between patients with different HLA risk antigens were investigated with regard to sex, age at diagnosis, season of year and calendar year at diagnosis of the disease. The study consisted of 293 HLA-typed patients from the Department of Paediatrics, University of Oulu, Oulu, Finland. HLA-Dw2 was extremely rare among diabetic patients, whereas Dw3 and Dw4 were associated with increased risk in this as in other series. Male patients more often had the HLA-A1 antigen than females. On comparison of the Dw3 positive patients, boys more frequently had the com-
\end{abstract}

bination $\mathrm{A} 1, \mathrm{~B} 8$ than girls. $\mathrm{A} 1, \mathrm{~B} 8$-positive patients were more often diagnosed during the warm months, in the late summer and autumn. Patients with both Dw3 and Dw4 were younger at diagnosis when compared with the rest of the patients. The results support the concept of heterogeneity in the pathogenesis of Type 1 diabetes associated with HLA-linked genetic determinants.

Key words: Type 1 diabetes, HLA, seasonal variation, age at diagnosis, sex.
Both hereditary and environmental factors play a role in the pathogenesis of Type 1 (insulin-dependent) diabetes mellitus. The hereditary factors associated with HLA genes, most probably exert their influence via the immune system. A seasonal variation in the incidence of Type 1 diabetes has been established in many reports [1-6], with peaks occurring during the cold months of the year. The variation seems to be age- (and possibly sex-) dependent and is not found among the youngest children [4]. The seasonal variation has been suggested as being connected with various environmental factors, viral infections being one of the most interesting to which the attempts of investigators have been directed. It is probable that many viruses in addition to Coxsackie B and mumps may have diabetogenic effects, although perhaps via different pathogenetic pathways, making it difficult to show an association.

There is some evidence of differences in the characteristics of patients with the HLA antigens DR3 and DR4 considered separately, and the disease risk is highest when both these antigens are present [7-9].

The purpose of the present study was to look for further evidence of the heterogeneity within Type 1 diabetes by evaluating possible differences in the HLA antigen types of patients grouped according to sex, age at diagnosis, season at diagnosis and year of onset.

\section{Subjects and methods}

\section{Subjects}

In Finland the initial care of newly-diagnosed diabetic children takes place in the paediatric wards of central and regional hospitals. Exact data about the annual incidence of diabetes in children within a cer- tain area are available directly from the hospital records of that area, and thus the ascertainment in this study can be considered nearly complete. Epidemilogical studies on the incidence of Type 1 diabetes in children in Finland have also been possible with the aid of the Central Drug Registry's data [6].

Two-hundred and ninety-three HLA-typed patients with Type 1 diabetes ( 171 boys, 122 girls) from the Department of Paediatrics, University of Oulu, were included in the study; two hundred and seventy-three of them were diagnosed during the years 1968-1983. The total number of new Type 1 diabetic cases recorded during the years 1968-1983 was 338 (191 boys and 147 girls). All patients had been typed for HLA-A and -B antigens, and 290 for the C-locus. D-typing results were available for 269 patients.

The patients were transferred to other diabetic units after cessation of growth. As a result, HLA data are missing for some patients who were near to or at puberty at the onset of the disease during the earliest years of the study period. Younger patients are thus relatively over-represented among the HLA-typed patients.

\section{Methods}

Serological Typing for HLA-A, -B and -C antigens was carried out by a standard two-stage microlymphocytotoxicity test [10]. The presence of the following antigens was determined; A1, 2, 3, 9, 10, 11, w19, 28; $\mathrm{B} 5,7,8,12,13,14,15,16,17,18,21$, w22, 27, 35, 40; Cw1, w2, w3, and w4. HLA-D typing was done by mixed lymphocyte culture using local homozygous typing cells defining the specificities Dw1, w2, w3, w4, and w6 [11]. The control subjects for HLA typing consisted of healthy unrelated blood donors and laboratory personnel from the same area. Ethnically the population of the area covered in this study in homogenous.

In the study of the annual and seasonal incidence, the day of diagnosis was regarded as the date of onset of the disease. In studying the seasonal incidence, the calendar year was divided first into two halves, the warm and cold seasons: from May to October the mean temperature in this area is over $0^{\circ} \mathrm{C}$ according to long-term statistics, and from November to April the mean temperature is below $0^{\circ} \mathrm{C}$. The resulting halves were further divided into two 3 -month periods: May-July, August-October, November-January and February-April. 
Table 1. HLA specificities in 281 unrelated Type 1 diabetic children and in 331 control subjects

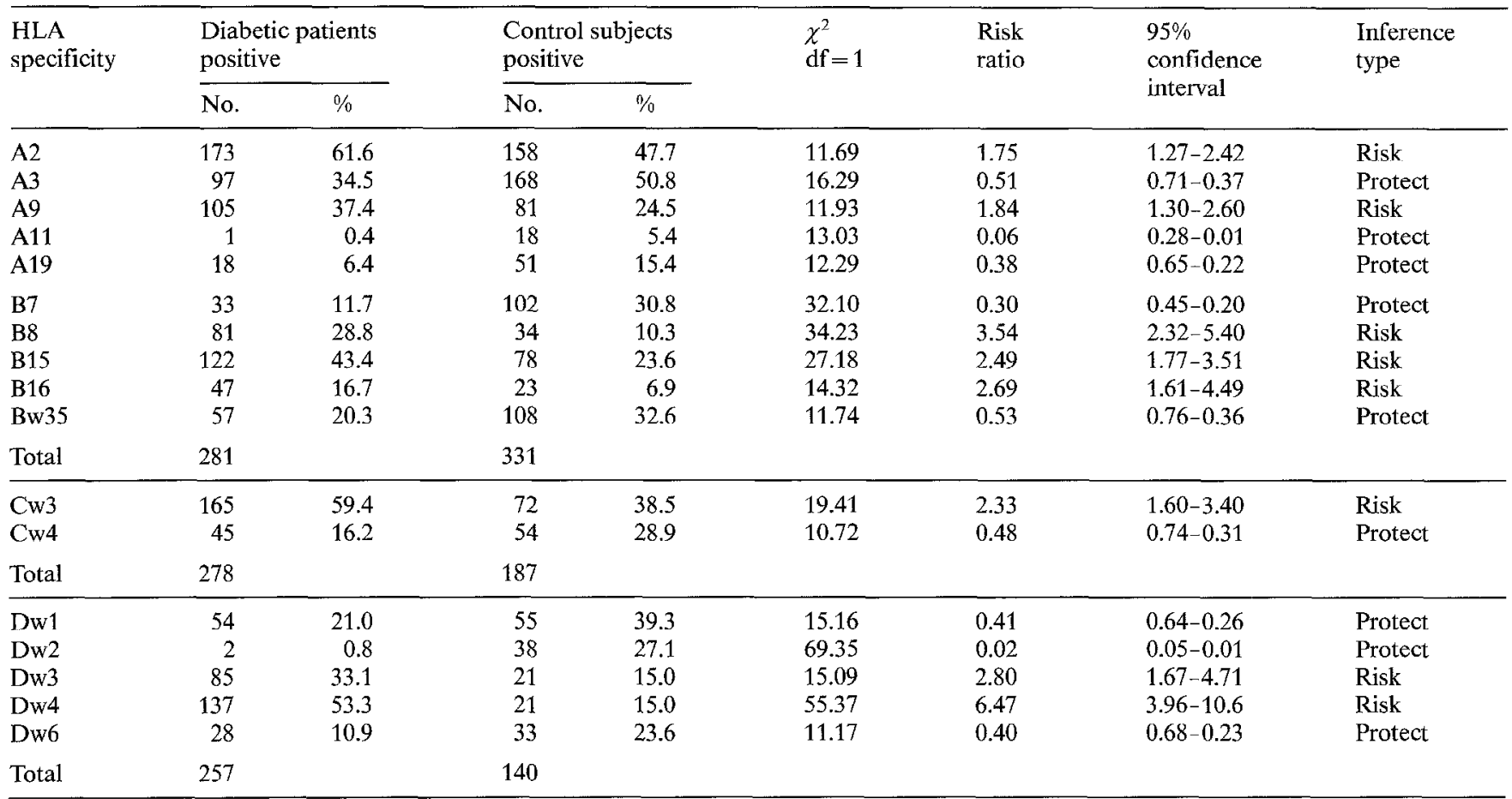

Table 1 is designed so that only definite associations ( $p<0.001$, one-tailed interpretation, not corrected for number of comparisons made) between specificities and Type 1 diabetes are shown. In all cases, either $p<0.05$ after correction for number of comparisons, or such correction is unnecessary because the association has previously been reported in other samples

Table 2. Age at diagnosis in children with Type 1 diabetes having both the risk specificities Dw3 and Dw4 compared with those patients who have only one or neither of these specificities.

\begin{tabular}{|c|c|c|c|c|c|c|c|c|c|}
\hline \multirow{3}{*}{$\begin{array}{l}\text { Specifi- } \\
\text { city }\end{array}$} & \multicolumn{9}{|c|}{ Age at diagnosis (cumulative frequencies) } \\
\hline & \multicolumn{2}{|c|}{3 years } & \multicolumn{2}{|c|}{6 years } & \multicolumn{2}{|c|}{9 years } & \multicolumn{2}{|c|}{12 years } & \multirow{2}{*}{$\begin{array}{l}\text { Total } \\
\text { No. }\end{array}$} \\
\hline & No. & $(\%)$ & No. & $(\%)$ & No. & $(\%)$ & No. & $(\%)$ & \\
\hline Dw3 & 4 & (8) & 19 & (36) & 34 & (64) & 44 & (83) & 53 \\
\hline Dw4 & 16 & (16) & 32 & (32) & 60 & (59) & 79 & (80) & 99 \\
\hline Dw3,Dw4 & 12 & (32) & 21 & (57) & 27 & (73) & 29 & (78) & 37 \\
\hline $\mathrm{Dx}$ & 9 & (9) & 33 & (34) & 56 & $(58)$ & 67 & (69) & 97 \\
\hline
\end{tabular}

$\mathrm{Dx}=$ neither Dw3 nor Dw4. The patients having both Dw3 and Dw4 were diagnosed younger than the rest of the patients. Twelve of the 41 diagnosed under the age of 3 years had this genotype as did 25 of the 249 aged $>3$ years $\left(\chi^{2}=11.33, p<0.001\right)$

The exact age (=the exact month) at diagnosis was not available for six HLA-typed patients, so that in the analyses dealing with the month of onset, the total number of patients is 287 . There were 12 siblingpairs among the patients; only the first proband of each pair is included in Table 1 giving the relative risks and results of the statistical analyses.

\section{Statistical analysis}

The relative risks ( $R R$ ) were calculated by the simple formula $\mathrm{ad} / \mathrm{bc}$ where $a$ and $b$ are the numbers of patients carrying and lacking the antigen, respectively, and $\mathrm{c}$ and $\mathrm{d}$ are the corresponding numbers for the controls. The $95 \%$ confidence limits for the relative risks were calculated by the formula described by Miettinen [12]. The distribution of HLA-antigens was tested using $\chi^{2}$, and Yates' correction was applied in cases where the number of expected values was 5 or less. The $\chi^{2}$ test was also applied to all the other discrete variables.

\section{Results}

Table 1 shows the HLA frequencies which differed in the diabetic children from those in the control subjects at the level $p<0.001$ without a correction for the number of antigens tested.

The most conspicuous difference between the patients and controls was the almost total lack of Dw2 antigen among the patients. The frequencies of Dw3 and Dw4 were strongly increased in the patients, as also were the antigens known to be in linkage disequilibrium with these: $\mathrm{A} 1, \mathrm{~B} 8$ and $\mathrm{A} 2, \mathrm{~B} 15, \mathrm{Cw} 3$. In addition increased frequencies of $\mathrm{A} 9$ and $\mathrm{B} 16$ were seen $(p<0.05$; after correction for number of comparisons).

Between sexes among diabetic patients a significant difference was found with respect to the antigen A1. It was present in $44(26 \%)$ of males and only $16(13 \%)$ of females $\left(\chi^{2}=6.21, p<0.05\right)$. Among Dw3-positive patients there was a sex difference so that the combination A1,B8 was found more often in Dw3-positive boys ( 26 out of 48) than in Dw3-positive girls (13 out of 42 ; $\chi^{2}=6.34, p<0.025$ ).

The patients with the antigen combination Dw3/Dw4 were diagnosed at an earlier age than patients with only one of these or lacking them altogether (Table 2, $\chi^{2}=11.33, p<0.001$ ).

Figure 1 indicates the numbers of Type 1 diabetic children diagnosed in each month, subdivided by age at diagnosis ( 0 to 4.9 years and 5 years or more). In the younger age group, 47 out of 83 were boys, and no seasonal variation was observed in this group. Among boys 

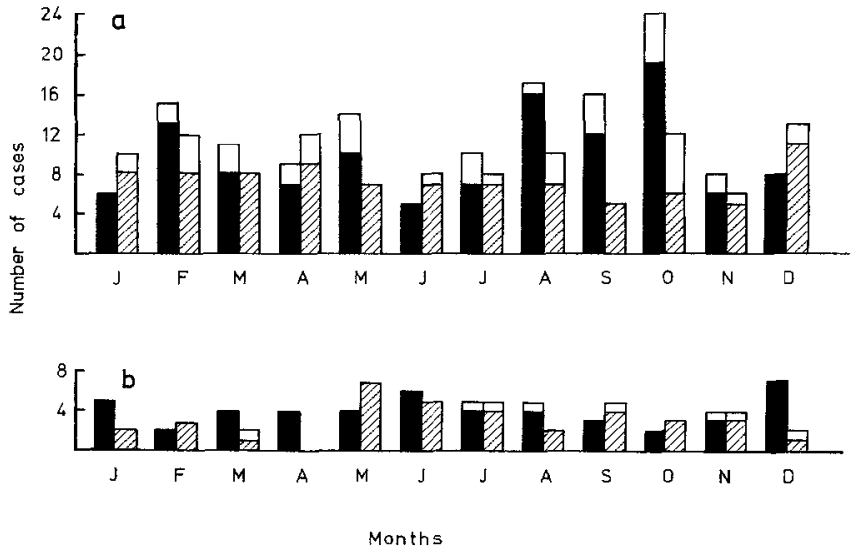

Fig. 1. Monthly incidence of new cases of Type 1 diabetes. All cases registered in the Department of Paediatrics, University of Oulu, Oulu, Finland, are included. Children aged 5 years or more at diagnosis (a), and children aged under 5 years (b), are indicated separately. The $\boldsymbol{\square}=$ boys, the $\mathbb{2}=$ girls, the $\square=$ patients who have not been HLAtyped. Boys over 5 years were diagnosed significantly more often during August-October than the rest of the year $\left(\chi^{2}=16.84, p<0.001\right)$

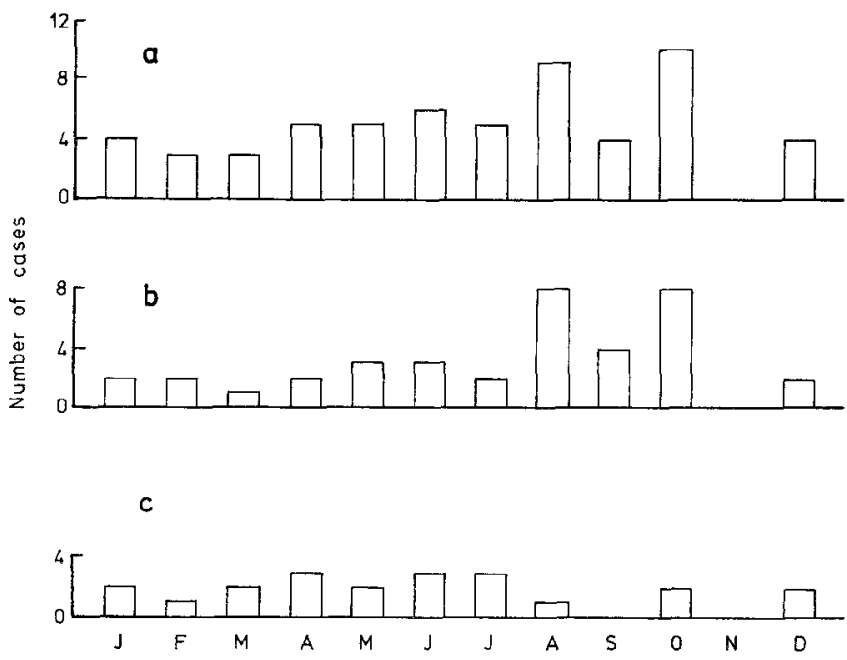

Fig. 2a-c. Monthly incidence of the children with Type 1 diabetes who were HLA B8 positive and aged $>5$ years at diagnosis. (a) both sexes, (b) boys, (c) girls. Boys with HLA-B8 were diagnosed significantly more often during the August-October period than the rest of the year $\left(\chi^{2}=17.60, p<0.001, \mathrm{df}=3\right.$; when comparing the observed incidence with assumed even incidence during each quarters of the year). The total number of HLA-typed children was 287

aged 5 years or more there was an increase in numbers diagnosed during the period August-October $(n=57)$ when compared with the rest of the year $(n=86$; $\chi^{2}=16.84, p<0.001$ ).

When the HLA distribution was studied in patients diagnosed during different seasons, those positive for HLA B8 showed a significant difference between warm ( $n=51$ out of 155) and cold ( $n=28$ out of 132) seasons $\left(\chi^{2}=4.88, p<0.05\right)$. The distribution of B8-positive patients, with peaks in May and August-October, was similar to that in the total patient population (Fig.1). Further analysis of the B8-positive patients diagnosed at the age of 5 years or more revealed that males having B8 were usually diagnosed during the autumn months (as- suming an even expected incidence during each quarter of the year: $\chi^{2}=17.60, \mathrm{df}=3, p<0.001$, Fig. 2). During this peak quarter (August-October) $20(42 \%)$ out of the 48 HLA-typed boys had HLA B8, and when the rest of the year was pooled together there were $17(25 \%)$ HLA B8-positive boys out of 68 . In this comparison $\chi^{2}=3.60$, $0.05<p<0.1$. The seasonal variation at diagnosis was also seen with regard to type A1 in males; 20 out of 44 $(45 \%)$ were diagnosed during the 3 autumn months $\left(\chi^{2}=9.82, p<0.005\right)$.

The most common HLA antigen types, B15 and Dw4, did not show statistically significant seasonal variation overall, although boys having B15 were often diagnosed during the cold months and girls in warm months. The annual fluctuation in the incidence of new cases during the years 1968-83 differed from the random distribution between each year $\left(\chi^{2}=30.0, \mathrm{df}=15\right.$, $p<0.025)$. Frequencies of specific HLA types in each peak year were calculated but no significant overrepresentation of any particular HLA type was found.

\section{Discussion}

The most striking difference in HLA frequencies between patients and control subjects was the greatly decreased frequency of Dw2 among the patients. This has been reported in several studies $[7,8,13]$ and it is difficult to explain simply by a strong negative linkage with the susceptibility factors.

In addition to the well known connection with both B8/Dw3 and B15/Dw4, the results indicate an association of Type 1 diabetes with HLA-A9 and B16 in children in Northern Finland, as reported previously [14]. The suggestion that the haplotype A9/B16 forms a separate diabetes-susceptible unit in HLA genetics, similar to $\mathrm{A} 1 / \mathrm{B} 8$ and $\mathrm{A} 2 / \mathrm{B} 15$, is supported by other specific characteristics associated with this combination $[14,15]$. Although A9/B16 is not associated with Dw4, it does, however, seem to be associated with DR4 [16].

The statistical treatment of the distribution data is somewhat problematic. However, since previous studies show that the seasonal variation is mainly found in patients older than 5 years of age and because the peak in August-October was found also in a previous Scandinavian study [5], the comparison of HLA frequencies of the patients in this peak using the $\chi^{2}$-test seems reasonable.

Our results suggest that the seasonal variation in the incidence of Type 1 diabetes in children, with peaks in spring and autumn, found in earlier studies, could be a consequence of differing susceptibility of patients with different HLA types to various environmental factors. Furthermore, some difference(s) in susceptibility between boys and girls may influence the presence of two separate peaks.

It has been suggested that the known distortion of the sex ratio in Type 1 diabetes in children is a consequence of hereditary factors, based on the increased inheritance of haplotype A1/B8 in male patients [17]. In 
our study the only difference in the HLA types between the sexes was the increase of A1 among diabetic boys, and when Dw3-positive boys and girls were compared, the other antigens of the haplotype, A1 and B8, were significantly more common in boys. The autumn peak (August-October) of new cases was, in this series, caused by the concentration of boys older than 5 years at diagnosis and with HLA antigens of the "autoimmune" haplotype A1,B8,Dw3.

Rolles et al. suggested a connection between Coxsackie $B$ virus infection and a raised incidence of Type 1 diabetes among HLA-B8-positive individuals [18]. In their study, the accumulation of B8-positive patients occurred later in the year than in our series. Weinberg et al. found that DR3-positive patients showed a seasonal diagnosis pattern while the DR3-negative cases did not show significant seasonality of diagnosis [19]. We found seasonality with respect to the date of diagnosis in B8-positive patients, but the patterns of the peaks were different in the two studies. The varying in patterns of environmental factors in different countries makes direct comparisons between studies very complicated. It remains to be clarified whether the difference found between sexes in the present study is somehow associated with differences in the susceptibility to certain viruses in HLA-B8,Dw3-positive patients. It should also be noted that the pathogenetic mechanism of diabetes in children with $\mathrm{A} 1, \mathrm{~B} 8, \mathrm{Dw} 3$ antigens may be different from that in young adults with an autoimmune form of the disease, associated with persistent autoimmune phenomena and female preponderance [20].

DR3/DR4 heterozygous patients have been reported to be diagnosed significantly more often before the age of 20 years than other patients [9]. Our results indicate that the high-risk combination Dw3/Dw4 has an influence on the penentrance of the disease even during the earliest years of life. This also supports the theory that at least two different genes have an effect on the manifestation of Type 1 diabetes. It should, however, be noted that some of the results in the present study are only preliminary, and unless confirmed in other studies they can not be held as proven.

Acknowledgements. The study was financially supported by the Alma and K. A.Snellman Foundation, Oulu, Finland (A. M., J.I.), the Diabetes Research Foundation in Finland (A.M.) and the Hoechst Fennica Research Foundation (J.I.). The authors wish to thank Mrs. M. Siitonen for her skilful technical assistance in the HLA-typing.

\section{References}

1. Adams SF (1926) The seasonal variation in the onset of acute diabetes. Arch Intern Med 37: 861-864

2. Somersalo O, Hiekkala H, Rantakallio P, Tuuteri L (1960) Studies in childhood diabetes: review of 359 cases. Ann Paediatr Fenn 6: 253-274

3. Gamble DR, Taylor KW (1969) Seasonal incidence of diabetes mellitus. Br Med J 3: 631-633
4. Gray RS, Duncan LJP, Clarke BF (1979) Seasonal onset of insulin dependent diabetes in relation to sex and age at onset. Diabetologia 17:29-32

5. Christau B, Akerblom H, Joner G, Dahlqvist G, Ludvigsson J, Nerup J (1981) Incidence of childhood insulin-dependent diabetes mellitus in Denmark, Finland, Norway and Sweden. A workshop report. Acta Endocrinol 98 (Suppl 245): 68-80

6. Reunanen A, Åkerblom HK, Käär M-L (1982) Prevalence and ten-year (1970-1979) incidence of insulin-dependent diabetes mellitus in children and adolescents in Finland. Acta Paediatr Scand 71: 893-899

7. Platz P, Jakobsen BK, Morling N, Ryder LP, Svejgaard A, Thomsen M, Christy M, Kromann H, Benn J, Nerup J, Green A, Hauge $M$ (1981) HLA-D and -DR antigens in genetic analysis of insulin dependent diabetes mellitus. Diabetologia 21: 108-115

8. Wolf E, Spencer KM, Cudworth AG (1983) The genetic susceptibility to Type 1 (insulin-dependent) diabetes: Analysis of the HLA-DR association. Diabetologia 24: 224-230

9. Johnston C, Pyke DA, Cudworth AG, Wolf E (1983) HLA-DR typing in identical twins with insulin-dependent diabetes: difference between concordant and discordant pairs. Br Med $\mathrm{J} 1$ : 253-255

10. Turunen $O$, Lundquist $C$, Julin $M$, Holmlund $G$, Tiilikainen $A$, de la Chapelle A (1979) Stimulatory and cytotoxic activity on human adult and fetal lymphocytes by heterologous antihuman fetal lymphocyte sera. Transplant Proc 27: 304-308

11. Ilonen J, Lagerstedt A, Koskimies S, Reunanen M (1983) HLADw1 and BfF as protective markers in multiple sclerosis. $J$ Neuroimmunol 5: 283-288

12. Miettinen OS (1976) Estimability and estimation in case-referent studies. Am J Epidemiol 103: 226-235

13. Ilonen J, Herva E, Tiilikainen A, Åkerblom HK, Koivukangas T, Kouvalainen K (1978) HLA-Dw2 as a marker of resistance against juvenile diabetes mellitus. Tissue Antigens 11: 144-146

14. Ilonen J, Åkerblom HK, Tiilikainen A, Mustonen A, Herva E, Koskimies S, Kouvalainen K (1982) Increase of HLA haplotype A9-Bw16 in familial insulin-dependent diabetes mellitus in Northern Finland. Acta Diabetol Lat 19:167-174

15. Mustonen A, Ilonen J, Åkerblom HK, Tiilikainen A (1982) An islet-cell antibody negative form of insulin-dependent diabetes mellitus (IDD) associated with HLA antigens A9 and Bw16. Clin Exp Immunol 48: 213-217

16. Mustonen A, Ilonen J, Surcel H-M, Åkerblom HK (1984) A "new" DR4 associated D specificity "JA" in Type 1 (insulin-dependent) diabetes: A9,Bw16,DJA,DR4 haplotype. Diabetologia 27 (Suppl): $126-128$

17. Cudworth AG, Wolf E, Gorsuch AN, Festenstein H (1979) A new look at HLA genetics with particular reference to Type-1 diabetes. Lancet 2: 389-391

18. Rolles CJ, Raynor PHW, Mackintosh P (1975) Aetiology of juvenile diabetes. Lancet 2: 230 (Letter)

19. Weinberg CR, Dornan TL, Hansen JA, Raghu PK, Palmer JP (1984) HLA-related heterogeneity in seasonal patterns of diagnosis in Type 1 (insulin-dependent) diabetes. Diabetologia 26: 199-202

20. Cudworth AG, Wolf E (1982) The genetic susceptibility to Type 1 (insulin-dependent) diabetes mellitus. Clin Endocrinol Metab 11: $389-408$

Received: 25 June 1984

and in revised form: 28 May 1985

Dr. Aki Mustonen

Department of Paediatrics

University of Oulu

SF-90220 Oulu 22

Finland 